\title{
Huisartsenzorg voor mensen met een verstandelijke beperking
}

\author{
Samenvatting \\ Cardol M, Dusseljee JC, Rijken PM, Van Schrojenstein Lantman-de Valk \\ HMJ. Huisartsenzorg voor mensen met een verstandelijke beperking. \\ Huisarts Wet 2011;54(7):354-8.
}

ACHTERGROND Mensen met een verstandelijke beperking maken vaker dan voorheen gebruik van de huisartsenzorg. Dat vraagt specifieke kennis en vaardigheden van de huisarts. We onderzochten de ervaringen van de naasten van deze patiënten - merendeels familieleden.

METHODE In 2009 hielden wij gestructureerde telefonische interviews met 216 naasten van mensen met een lichte of matige verstandelijke beperking.

RESULTATEN De naasten die meegingen naar de huisarts waren tevreden over de huisartsenzorg. Wel was ruim $75 \%$ van mening dat de betreffende persoon met verstandelijke beperking niet alleen naar de huisarts kon. Van de mensen met een verstandelijke beperking in het onderzoek had $20 \%$ in het afgelopen jaar geen huisarts bezocht en ook geen andere arts. Slechts enkelen hadden contact gehad met een arts voor verstandelijk gehandicapten.

CONCLUSIE De naasten van personen met een verstandelijke beperking zijn tevreden over de huisartsenzorg aan hun familielid. Een relatief groot aantal mensen met een verstandelijke beperking echter blijkt het afgelopen jaar geen enkele arts bezocht te hebben, en dat roept de vraag op of hun gezondheid wel voldoende gevolgd wordt. Men zou moeten nagaan in hoeverre mensen met een verstandelijke beperking deelnemen aan preventieprogramma's.

\section{INLEIDING}

$M$ ensen met een verstandelijke beperking (VB) wonen vaker dan voorheen in woonwijken en maken ook vaker gebruik van de huisartsenzorg in de buurt..$^{1-3}$ Bij een gemiddelde huisartsenpraktijk staan ongeveer tien patiënten met een VB ingeschreven. De spreiding is groot; sommige huisartsenpraktijken hebben nauwelijks ingeschreven patiënten met een $\mathrm{VB}$, andere wel zeventig. ${ }^{3}$

Huisartsenzorg voor mensen met een VB is in twee opzichten bijzonder. Ten eerste hebben zij ongeveer twee keer zoveel kans op gezondheidsproblemen als mensen zonder een VB. ${ }^{2-5}$ Relatief vaak voorkomende gezondheidsproblemen zijn epilepsie, cerebrale parese, maag-darmproblemen, hart- en vaatziekten en problemen met horen en zien.,6-8 Mensen met een VB worden ouder dan voorheen, maar de veroudering kan bij hen al vanaf het vijftigste levensjaar voor gezondheidsproblemen zorgen. ${ }^{9}$

Ten tweede verloopt de communicatie met de huisarts anders. ${ }^{5}$ Niet alle mensen met een VB kunnen hun gezondheids-

NIVEL, Postbus 1568, 3500 BN Utrecht: dr. M. Cardol, senior onderzoeker; J.C. Dusseljee, onderzoeker; dr. P.M. Rijken, programmaleider. UMC Sint Radboud, afdeling Eerstelijnsgeneeskunde, Nijmegen: prof.dr. H.M.J. van Schrojenstein Lantman-de Valk, arts verstandelijk gehandicapten, hoogleraar Geneeskunde voor mensen met verstandelijke beperkingen. • Correspondentie: m.cardol@nivel.nl • Mogelijke belangenverstrengeling: niets aangegeven. problemen even goed verwoorden en voor de huisarts is het soms lastig om die problemen goed te interpreteren. ${ }^{1}$ Mensen met een VB gaan daarom vaak samen met een familielid of begeleider naar de huisarts. Ze zijn ook verder voor hun gezondheid grotendeels aangewezen op hun naasten en begeleiders. ${ }^{10}$

Huisartsen, onderzoekers en mensen uit de praktijk hebben zich wel afgevraagd of de huisarts voldoende is toegerust voor de medische zorg aan mensen met een VB. ${ }^{11-12}$ Huisartsen zelf geven aan dat zij te weinig weten over specifieke aandoeningen zoals epilepsie, dat de communicatie soms moeizaam is en dat het allemaal te veel tijd kost. Toch vinden zij zichzelf de aangewezen persoon om medische zorg te verlenen aan mensen met een VB. Zij kunnen daarbij baat hebben bij specialistische ondersteuning door een arts voor verstandelijk gehandicapten (AVG), ${ }^{12}$ maar volgens de inspectie weten veel huisartsen de AVG niet te vinden. ${ }^{11}$ Het [kader] geeft een overzicht van de mogelijkheden voor verwijzing.

De huisarts ziet dus steeds meer patiënten met een VB, maar hoe het er bij zo'n bezoek nu precies aan toegaat is nooit onderzocht. Daarom vroegen wij de naasten van deze patienten (ouder, gastouder, broer of zus, soms ook een vriend of begeleider) naar hun ervaringen: hoe verloopt de communicatie tijdens zo'n consult en hebben zij weleens contact met een AVG?

\section{Wat is bekend?}

- Mensen met een verstandelijke beperking wonen vaker dan voorheen in woonwijken en maken vaker gebruik van huisartsenzorg in de buurt.

- De zorg voor mensen met een verstandelijke beperking vraagt specifieke kennis en vaardigheden van huisartsen.

- Afhankelijkheid van anderen kan de toegang tot de huisartsenzorg voor mensen met een verstandelijke beperking belemmeren.

\section{Wat is nieuw?}

- Familieleden zijn tevreden over de huisartsenzorg voor hun familielid met een verstandelijke beperking.

- Ook mensen met een lichte verstandelijke beperking zijn voor hun huisartsenbezoek aangewezen op familie of begeleiders.

- In grote meerderheid vinden familieleden de huisarts de eerst aangewezene bij gezondheidsproblemen van mensen met een lichte of matige verstandelijke beperking.

- Toch had $20 \%$ van de mensen met een verstandelijke beperking gedurende het onderzoeksjaar geen contact met hun huisarts, noch met andere artsen.

- Slechts enkele mensen met een lichte of matige verstandelijke beperking consulteerden in het onderzoeksjaar een arts voor verstandelijk gehandicapten. 


\section{METHODE}

\section{Onderzoekspopulatie}

In 2006 heeft het NIVEL het Panel Samen Leven (PSL) opgezet. In dit panel zitten mensen van 15 jaar of ouder met een lichte of matige verstandelijke beperking, en hun naasten..$^{13}$ Deze naasten zijn in overgrote meerderheid familieleden (ouder, gastouder, broer of zus), in een enkel geval is het de begeleider uit de woonvoorziening of een vriend; we zullen hen daarom hierna collectief aanduiden als 'familieleden'. Mensen met een VB hebben moeite met leren, begrijpen en redeneren, en met sociale en praktische vaardigheden. ${ }^{14}$ Mensen met een lichte VB kunnen zich daarbij meestal redelijk uitdrukken en (begeleid) zelfstandig wonen, maar worden vanwege hun verbale capaciteiten vaak overschat. Mensen met een matige VB wonen vaker in een woonvoorziening. Zij kunnen meestal wel aangeven wat ze willen, maar hebben op bijna alle levensgebieden ondersteuning nodig.

De panelleden uit woonvoorzieningen zijn geworven via 55 wooninstellingen in Nederland, de leden die (begeleid) zelfstandig wonen via een steekproef van 87 huisartsenpraktijken verspreid over Nederland. De huisartsenpraktijken spoorden potentiële panelleden op aan de hand van een checklist. ${ }^{15} \mathrm{Het}$ PSL is representatief voor wat betreft leeftijd, geslacht en verdeling naar lichte en matige VB. ${ }^{16}$

In 2009 telde het PSL 641 panelleden met een VB en $238 \mathrm{fa}$ milieleden. Wij vroegen deze naasten in een telefonisch interview naar het gebruik van huisartsenzorg door hun familielid met VB in dat jaar, en naar hun ervaringen daarmee. Bij de huisarts of de wooninstelling vroegen wij de achtergrondkenmerken op van de persoon met VB, zoals de mate van de beperking en de woonsituatie. Uiteindelijk beschikten we over 216 afgeronde interviews, een respons van 91\%.

\section{Interviews}

Wij interviewden de familieleden aan de hand van een gestructureerde vragenlijst. Zij kregen aan het begin van het interview twee selectievragen: was de persoon met VB het afgelopen jaar bij een huisarts geweest en zo ja, was er een familielid meegegaan? Op basis hiervan verdeelden we de interviews in drie groepen: 1) de persoon met VB was bij de huisarts geweest en er ging een familielid mee, 2) de persoon met VB was bij de huisarts geweest zonder dat er een familielid bij was, maar die wist ervan, en 3 ) de persoon met VB had dat jaar volgens de familie geen huisarts bezocht.

Groep 1 vroegen wij naar het aantal keren dat de persoon met VB bij de huisarts was geweest, de reden voor het bezoek, wie de afspraak had gemaakt, hoe het contact met de huisarts was, eventuele doorverwijzing naar een AVG en de tevredenheid met het bezoek aan de huisarts. Groep 2 kreeg dezelfde vragen, met uitzondering van vragen over het maken van de afspraak en het verloop van het consult. Groep 3 vroegen wij welke arts het belangrijkste aanspreekpunt was voor gezondheidsproblemen: huisarts, AVG, specialist of andere arts?
Huisartsenzorg aan mensen met een verstandelijke beperking

- Zorgverzekeringswet: patiënten met een verstandelijke beperking staan op naam ingeschreven in de huisartsenpraktijk.

- AWBZ: patiënten met een indicatie AWBZ-verblijf en -behandeling en die in een woonvoorziening verblijven, kunnen niet op naam worden ingeschreven (NONI). Declaratie van de kosten is geregeld in het contract met de zorginstelling.

- Passantentarief: bij incidentele zorg (bijvoorbeeld op vakanties) kan de huisarts het passantentarief in rekening brengen.

\section{Verwijzing naar een arts verstandelijk gehandicapten (AVG)}

- Zorgverzekeringswet: de huisarts kan mensen voor wie aanspraken en financiering via de zorgverzekeringswet lopen, doorverwijzen naar de AVG voor een consultatie.

- CIZ-indicatie: voor monodisciplinaire consultatie van de AVG is geen CIZ-indicatie nodig, voor multidisciplinaire inzet (bijvoorbeeld ook paramedici en gedragsdeskundigen) is wel een CIZ-indicatie nodig.

- AVG-polikliniek: de huisarts kan een verwijsbrief met de vraagstelling en informatie over de medische voorgeschiedenis sturen naar een AVG-polikliniek in de buurt (te vinden via http://www.nvavg.nl > 'Verwijzing naar AVG').

- Informatie voor huisartsen: is te downloaden van http://www.nvavg.nl/bestanden/ NVAVG-folder/folder-nvavg.pdf.

\section{Analyse}

Alle antwoorden uit de interviews rekenden wij om naar percentages op basis van het aantal respondenten. Met behulp van chikwadraattoetsen zochten wij naar verschillen in achtergrondkenmerken, waarbij de grens voor significantie lag bij een $\mathrm{p}$-waarde van 0,05 .

\section{RESULTATEN}

Wij vroegen de 216 respondenten naar het huisartsenbezoek van 95 mensen met een lichte en 116 mensen met een matige VB. Van 5 personen was de ernst van de beperking onbekend. Honderdrieëntachtig respondenten $(85 \%)$ waren familie van de persoon met VB: ouder, gastouder, broer of zus [tabel 1]. De meeste mensen met een VB verkeerden volgens de responden-

\section{Abstract}

Cardol M, Dusseljee JC, Rijken PM, Van Schrojenstein Lantman-de Valk HMJ. General practice care for people with intellectual disabilities: perspectives of their relatives. Huisarts Wet 2011;54(7):354-8.

BACKGround People with an intellectual disability (ID) visit primary care services more often than in the past. This requires general practitioners to have appropriate knowledge and skills. We investigated what the relatives thought of the primary care services used by their family members with mild or moderate intellectual disability.

METHOD In 2009, 216 relatives of people with ID participated in a structured telephone interview.

RESULTS The relatives who accompanied their family member with ID to the general practitioner were satisfied with the care provided. Moreover, about $75 \%$ of the respondents thought that people with ID should not visit a general practitioner or primary care service on their own. About $20 \%$ of the people with ID in our study population had not visited a general practitioner or other doctor in the last year, and only a few had been in contact with a doctor specialized in the care for people with ID.

CONCLUSION The relatives and carers of people with ID were satisfied with the care provided. However, the relatively large number of patients who had not visited a doctor in the past year raises the question whether the health of individuals with ID is being adequately monitored. It is important to evaluate to what extent people with ID have an annual health check-up or participate in preventive care programmes. 
Tabel 1 Kenmerken van de onderzoekspopulatie ( $n=216$ mensen met een verstandelijke beperking)*

\begin{tabular}{|c|c|c|c|}
\hline & & $\begin{array}{l}\text { Lichte beperking } \\
(\mathrm{n}=95)\end{array}$ & $\begin{array}{l}\text { Matige beperking } \\
(\mathrm{n}=116)\end{array}$ \\
\hline \multicolumn{4}{|l|}{ Mensen met een $V B$} \\
\hline - vrouwen & & 45 & 57 \\
\hline - mannen & & 50 & 59 \\
\hline - jonger dan 50 jaar & & 60 & 80 \\
\hline - 50 jaar of ouder & & 35 & 36 \\
\hline \multicolumn{4}{|l|}{ Ervaren gezondheid volgens naasten } \\
\hline - uitstekend-(zeer) goed & & 57 & 85 \\
\hline - matig-slecht & & 17 & 15 \\
\hline - onbekend & & 21 & 16 \\
\hline \multicolumn{4}{|l|}{ Beperkingen volgens huisarts/instellingsarts } \\
\hline - visusprobleem & & 4 & 9 \\
\hline - gehoorprobleem & & 3 & 8 \\
\hline - lichamelijke (motorische) beperking & & 15 & 22 \\
\hline - gedragsprobleem & & 5 & 12 \\
\hline - psychiatrische problematiek & & 6 & 4 \\
\hline - epilepsie & & 10 & 8 \\
\hline - geen beperking & & 29 & 23 \\
\hline \multicolumn{4}{|l|}{ Respondenten } \\
\hline - familie (ouder, gastouder, broer, zus) & 183 & & \\
\hline - professionele begeleider & 8 & & \\
\hline - anders & 3 & & \\
\hline - onbekend & 22 & & \\
\hline
\end{tabular}

* De mate van de verstandelijke beperking ontbreekt voor 5 mensen.

Figuur Stroomdiagram onderzoeksgroep $(n=216$ mensen met een verstandelijke beperking)

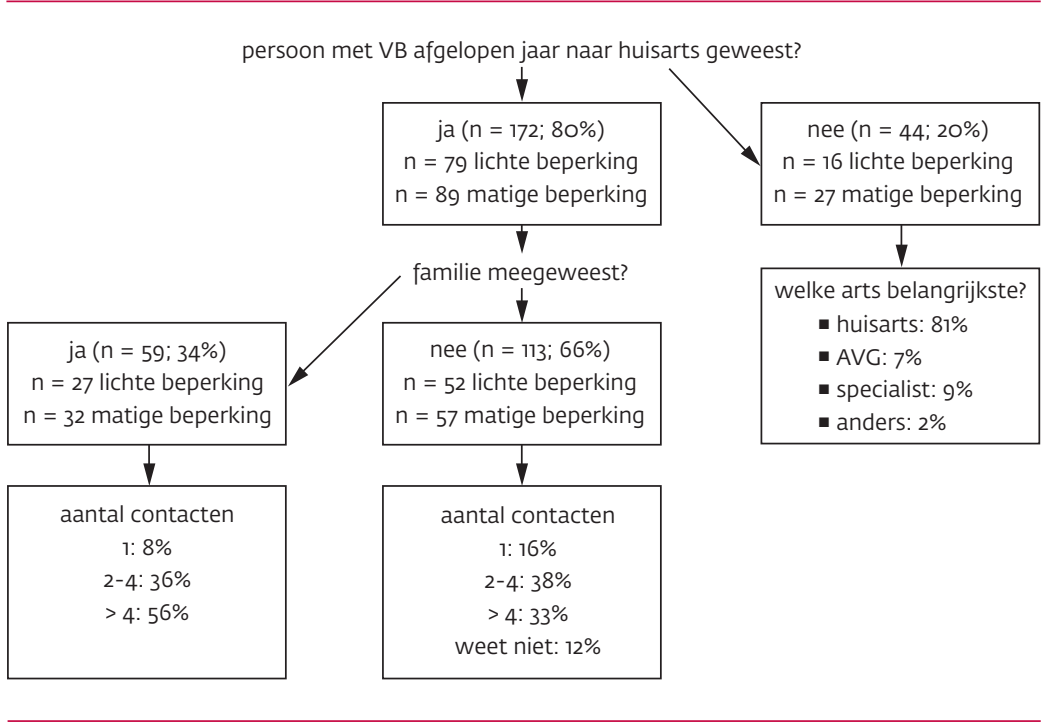

ten in goede gezondheid, al zeiden 42 respondenten dat ze dat niet konden inschatten. Van de mensen met een VB woonde $79 \%$ in een woonwijk ( $7 \%$ zelfstandig, 10\% bij familie, $62 \%$ in een begeleide woonvorm) en 21\% op of vlakbij een instellingsterrein. De [figuur] laat zien hoe de drie groepen zijn samengesteld.
Ongeveer $80 \%$ van de mensen met een VB was het afgelopen jaar naar de huisarts geweest, voor 20\% was het bezoek langer dan een jaar geleden. Bij ruim eenderde (34\%) van de bezoeken was een familielid meegegaan, bij tweederde (66\%) ging de familie niet mee maar was zij wel op de hoogte van het bezoek aan de huisarts.

Wij vonden geen significant verband tussen het wel of niet meegaan van een familielid en de mate van de VB, de woonsituatie of de leeftijd. Het is dus niet zo dat er vaker of juist minder vaak een naaste meegaat naar de huisarts als iemand bijvoorbeeld een ernstiger beperking heeft, jonger is of zelfstandig woont.

Van de personen met VB gingen diegenen die ouder waren dan 50 jaar significant vaker voor controle naar de huisarts (26\%) dan diegenen die jonger waren dan 50 jaar (11\%). Laatstgenoemden bezochten de huisarts vaker in verband met een specifieke gezondheidsklacht. De reden voor het huisartsenbezoek was meestal een acute klacht zoals een brandwond of een hoofdwond die gehecht moest worden. Oog- en oorinfecties, epilepsie, diabetes, verkoudheid en moeheid werden regelmatig genoemd en in een klein aantal gevallen ging het om (vermoede) kanker, hartproblemen en dementie.

Ruim $75 \%$ van de 216 familieleden was van mening dat de persoon met VB eigenlijk niet of slechts met moeite alleen naar de huisarts kon. De ernst van de verstandelijke beperking - licht of matig - maakte daarbij geen verschil. De belangrijkste redenen om mee te gaan waren dat de patiënt niet zelfstandig kon reizen of problemen had met communiceren. Een aantal familieleden vond ook dat het afhing van het gezondheidsprobleem: voor een griepje kan een patiënt met een VB zelf wel naar de huisarts, maar voor ingewikkelder problemen niet.

\section{Groep 1: familie was meegeweest naar de huisarts}

Van de 172 respondenten die meldden dat hun naaste naar de huisarts was geweest, gaven er 59 (34\%) aan dat zij de persoon met VB daarbij hadden vergezeld. Het initiatief voor het consult lag in deze gevallen meestal bij de familie of bij de begeleider uit de wooninstelling [tabel 2]. Zij ondervonden geen moeilijkheden bij het maken van de afspraak. Eén familielid meldde dat de huisarts in eerste instantie niet wilde helpen.

Het verwoorden van het gezondheidsprobleem gebeurde bijna even vaak door het familielid als door de patiënt zelf, vaak vulden zij elkaar aan. Ruim eenderde van de respondenten meldde dat de huisarts zich in het consult vooral tot de patiënt richtte. Meer dan de helft vond dat de patiënt voldoende ruimte kreeg om mee te beslissen over de behandeling.

De huisarts verwees geen enkele patiënt naar een AVG. Geen van de familieleden gaf aan dat zij voor de huisartsenzorg de voorkeur gaven aan een AVG, en 90\% zei vertrouwen te hebben in de huisarts. Het gemiddelde rapportcijfer dat de huisarts kreeg was een acht en niemand gaflager dan een zes.

\section{Groep 2: familie was niet meegeweest naar de huisarts}

Van de 172 familieleden die meldden dat hun naaste naar 
de huisarts was geweest, zeiden er 113 (66\%) dat ze niet waren meegegaan. In deze gevallen was de afspraak meestal gemaakt door een begeleider van de wooninstelling (73\%) [tabel 2]. Negenentwintig familieleden (26\%) zeiden dat de persoon met VB zonder begeleiding naar de huisarts was gegaan. Dit waren vooral, maar niet uitsluitend, mensen met een lichte beperking. In groep 2 hadden 91 familieleden (81\%) vertrouwen in de huisarts en gaven er $3(3 \%)$ de voorkeur aan een AVG.

\section{Groep 3: de huisarts was niet bezocht}

Van de 44 familieleden (20\%) wier naaste het laatste jaar niet bij de huisarts was geweest, vonden er 36 (82\%) de huisarts het belangrijkste aanspreekpunt bij gezondheidsproblemen. Drie familieleden meldden dat de persoon met VB altijd een AVG bezocht en 4 dat de specialist diens belangrijkste arts was.

Nadere analyse liet zien dat deze groep van 44 personen met VB 33 mannen telde (75\%), en dat 37 personen (84\%) volgens de respondenten een goede tot uitstekende gezondheid bezaten. Twee personen waren matig gezond en van 5 personen kon de respondent niet zeggen hoe gezond zij waren. Op andere kenmerken, zoals de mate van beperking, de leeftijd en de woonsituatie, week deze groep niet significant af van degenen die wel naar de huisarts geweest waren.

\section{BESCHOUWINC}

\section{Beperkingen}

Het is belangrijk op te merken dat onze resultaten gebaseerd zijn op een telefonische enquête onder vooral familieleden van huisartspatiënten met een VB. Zij geven dus het perspec-
Tabel 2 Opvattingen van de familie over de bezoeken aan de huisarts $(n=172)$

\begin{tabular}{lll}
$\begin{array}{l}\text { Mee naar huisarts } \\
(n=59)\end{array}$ & $\begin{array}{l}\text { Niet mee naar huisarts } \\
(n=113)\end{array}$ \\
\hline
\end{tabular}

Wie nam het initiatief?

- patiënt

$7 \quad(12 \%)$

- naaste

25 (42\%)

- begeleider

- anders

$10(17 \%)$

Wie maakte de afspraak?

- patiënt

$3(5 \%)$

18 (16\%)

- naaste

- begeleider

- anders

2 (4\%)

$7 \quad(6 \%)$

Met wie sprak de huisarts vooral?

- patiënt

$21 \quad(36 \%)$

- naaste

- beiden

$30(51 \%)$

Kon de patiënt meebeslissen over de behandeling?

- meestal/altijd

- nooit/soms

- weet niet

Had de respondent vertrouwen in de huisarts? $53(90 \%)$

$93(82 \%)$ Verwijzing naar AVG

$0 \quad(0 \%)$

$0 \quad(0 \%)$

tief van de familie weer en zeggen niet per se iets over de tevredenheid van de huisartspatiënten zelf. Ook gelden zij niet voor mensen met een ernstige VB, voor zover deze bij de huisarts komen.

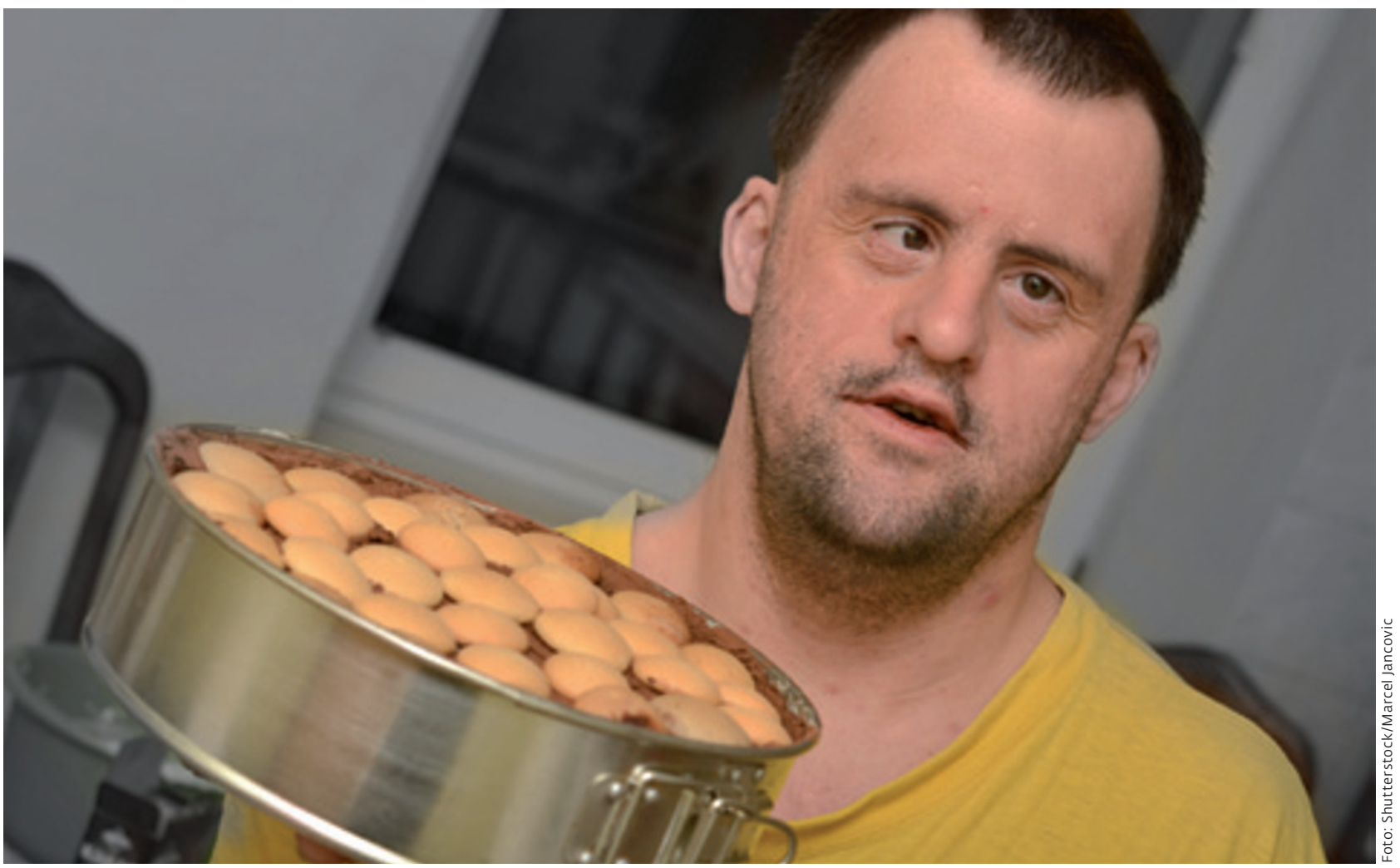


Een andere beperking is dat onze vragen gericht waren op het proces en niet op gezondheidsuitkomsten. Ons onderzoek laat daarom geen uitspraken toe over de kwaliteit van de huisartsenzorg aan mensen met een VB.

\section{Belangrijkste bevindingen}

De respondenten waren positief over de huisartsenzorg aan hun familielid met een VB. Slechts enkelen gaven de voorkeur aan een AVG. Degenen die meegingen naar de huisarts waren positiever over de communicatie tijdens het consult dan de literatuur doet vermoeden. ${ }^{11,17,18}$ Wel gaf ruim $75 \%$ van onze respondenten aan dat hun familielid eigenlijk niet alleen naar de huisarts kon. Afhankelijkheid van anderen kan de toegang tot de huisartsenzorg voor mensen met een VB belemmeren. ${ }^{1}$ Familie of begeleiders moeten het gezondheidsprobleem signaleren en tijd vrij maken om mee naar de huisarts te gaan. Medisch geschoolde begeleiding ontbreekt vaak, en dat maakt dat gezondheidsproblemen niet altijd of niet op tijd gesignaleerd worden. ${ }^{1,19}$ Bovendien is bekend dat de familie de gezondheid van een persoon met een VB vaak beter inschat dan deze in werkelijkheid is. ${ }^{20}$

Een tweede belangrijke bevinding is dat $20 \%$ van de mensen met een VB het afgelopen jaar geen huisarts had geconsulteerd, terwijl bijna al hun geïnterviewde familieleden aangeven dat de huisarts het belangrijkste aanspreekpunt is voor gezondheidsproblemen. Het kan zijn dat zij niet wisten dat de persoon met VB een huisarts bezocht had, maar het gevonden percentage is vergelijkbaar met dat in de algemene bevolking ${ }^{21}$ en met bevindingen uit onderzoek naar het gebruik van huisartsenzorg door mensen met een $\mathrm{VB}^{3}$. Weliswaar had een groot deel van de personen die niet bij de huisarts kwamen volgens hun familie een goede gezondheid - ook al bekende een aantal respondenten dat zij dit niet goed konden inschatten - maar heel zeker is dit niet, gezien de verhoogde kans op gezondheidsproblemen bij mensen met een VB en de niet altijd betrouwbare inschatting van de gezondheidstoestand door familie en begeleiders. Verschillende auteurs hebben gepleit voor gezondheidscontroles voor mensen met een VB, zodat men gezondheidsproblemen vroegtijdig kan signaleren, ${ }^{22,23}$ en deze controles zijn inderdaad effectief gebleken voor het opsporen van gezondheidsproblemen. ${ }^{1,10,24}$ Toch doen mensen met een VB minder vaak mee aan gezondheidsbevorderende en preventieve zorgprogramma's. ${ }^{1}$ Nader onderzoek naar hun deelname aan dergelijke zorgprogramma's lijkt ons dan ook zinvol.

Een derde bevinding uit ons onderzoek is dat slechts een paar personen met een VB in het onderzoeksjaar contact hadden gehad met een AVG. Misschien was dit ook niet nodig en konden de klachten prima door de huisarts worden afgehandeld. Uit ander onderzoek blijkt echter dat veel huisartsen niet precies weten welke aanvullende zorg een AVG biedt en hoe zij die kunnen benutten. ${ }^{11,25}$ Daarom lijkt een vervolgonderzoek naar de samenwerking tussen huisarts en AVG ons belangrijk. Ook uit dit onderzoek blijkt immers niet duidelijk dat huisartsen, familieleden en begeleiders de weg naar de AVG weten te vinden wanneer dat nodig is.

\section{LITERATUUR}

1 Felce D, Baxter H, Lowe K, Dunstan F, Houston H, Jones G, et al. The impact of repeated health checks for adults with intellectual disabilities. J App Res Intellect Disabil 2008;21:585-96.

2 Van Schrojenstein Lantman-de Valk HM, Metsemakers JFM, Haveman MJ, Crebolder HFJM. Health problems in people with intellectual disability in general practice: A comparative study. Fam Pract 2000;17:405-7.

3 Van Schrojenstein Lantman-de Valk HM, Straetmans J, Schellevis FC, Dinant G-J. Gezondheidsproblemen van mensen met een verstandelijke beperking in de huisartsenpraktijk. Huisarts Wet 2008;51:62-5.

4 Van Schrojenstein Lantman-de Valk HM. Health problems in people with intellectual disability: Aspects of morbidity in residential settings and primary health care [Proefschrift]. Maastricht: Universiteit Maastricht, 1998.

5 Van Schrojenstein Lantman-de Valk HM, Metsemakers JFM. De huisarts en de patiënt met een verstandelijke beperking. Maarssen: Elsevier $\mathrm{Ge}^{-}$ zondheidszorg, 2003.

6 Henderson A, Lynch SA, Wilkinson S, Hunter M. Adults with Down's syndrome: The prevalence of complications and health care in the community. Br J Gen Pract 2007;57:50-5.

7 Vallenga D, Tan F, Lendemeijer B, Grypdonck M, Boon P. Risico's voor mensen met epilepsie en een verstandelijke beperking, een literatuuroverzicht. Nederlands Tijdschrift voor de Zorg 2004;30:181-96.

8 Anwar AJ, Walker JD, Frier BM. Type 1 diabetes mellitus and Down's syndrome: Prevalence, management and diabetic complications. Diab Med 1998;15:160-3.

9 Haveman MJ, Maaskant MA. Defining fragility of the elderly severely mentally handicapped according to mortality risk, morbidity, motor handicaps and social functioning. J Ment Defic Res 1989;33:389-97.

10 Cooper S-A, Morrison J, Melville CA, Finlayson J, Allan L, Martin G, et al. Improving the health of people with intellectual disabilities: Outcomes of a health screening programme after 1 year. J Intellect Disabil Res 2006;50:667-77.

11 Kramer A, Kleefstra S, Kool T. Een kwestie van samenwerking en expertise: Medische zorg voor verstandelijk gehandicapten moet krachten bundelen. Med Contact 2005;60:1804-6.

12 Van Loon J, Knibbe J, Van Hove G. From institutional to community support: Consequences for medical care. J Appl Res Intellect Disabil 2005; $18: 175-80$

13 Cardol M, Speet, M, Rijken PM. Anders of toch niet? Deelname aan de samenleving van mensen met een lichte of matige verstandelijke beperking. Utrecht: NIVEL, 2007.

14 American Association of Intellectual and Developmental Disabilities. FAQ on intellectual disability Definition intellectual disability [internet] Washington (DC): AIDD, 2010. http://www.aamr.org/content_104.cfm, geraadpleegd mei 2011.

15 Van Schrojenstein Lantman-de Valk HM, Metsemakers JFM, SoomersTurlings JMSJG, Haveman MJ, Crebolder HFJM. People with intellectual disabilities in general practice: Case definition and case finding. J Intellect Disabil Res 1997;41:373-9.

16 Van den Hoogen P, Cardol M, Spreeuwenberg P, Rijken M. Deelname aan de samenleving van mensen met een beperking. Utrecht: NIVEL, 2010.

17 Landelijke Huisartsen Vereniging, Nederlandse Vereniging voor Artsen van Verstandelijk Gehandicapten. Handreiking huisarts en AVG: Optimale medische zorg voor mensen met een verstandelijke beperking. Utrecht: LHV/NVAVG, 2010.

18 Phillips A, Morrison J, Davis RW. General practitioners' educational needs in intellectual disability health. J Intellect Disabil Res 2004;48:142-9.

19 Leemrijse CJ, Pisters MF. Quick scan kwaliteit en veiligheid van ambulante zorg voor mensen met een verstandelijke beperking. Utrecht: NIVEL, 2009.

20 Evenhuis HM. Medical aspects of ageing in a population with intellectual disability, III: Mobility, internal conditions and cancer. J Intellect Disabil Res 1997;41:8-18.

21 Landelijk Informatie Netwerk Huisartsenzorg. Feiten en cijfers over huis artsenzorg in Nederland. Utrecht: NIVEL, 2010. http://www.nivel.nl/oc2/ page.asp?PageID = 12918\&path =/Startpunt/subsites/LINH. Geraadpleegd november 2010 .

22 Harrison S, Berry L. Improving primary care services for people with learning disability. Nurs Times 2005;101:38-40.

23 Van Schrojenstein Lantman-de Valk HM, Walsh PN. Managing health problems in people with intellectual disabilities. BMJ 2008;337:a2507.

24 Lennox N, Bain C, Rey-Conde T, Purdie D, Bush R, Pandeya N. Effects of a comprehensive health assessment programme for Australian adults with intellectual disability: A cluster randomized trial. Int J Epidemio 2007;36:139-46.

25 Wesseling $M$, Van Wijlick E. Medische zorg voor mensen met een verstandelijke handicap: AWBZ of zorgverzekeringswet? Utrecht: Projectenbureau KNMG, 2008. 